\title{
How to Use Design Thinking on Trash Bank Process Modeling?
}

\author{
Ferra Arik Tridalestari ${ }^{1}$, Hanung Nindito Prasetyo ${ }^{2 *}$, Wawa Wikusna ${ }^{2}$ \\ ${ }^{1}$ Dept. of Digital Business, Universitas PGRI Yogyakarta, Bantul, DI Yogyakarta 55182, Indonesia \\ ${ }^{2}$ Dept. of Information System Diploma, School of Applied Science, Telkom University, Jawa Barat 40257, Indonesia
}

Corresponding Author Email: hanungnp@telkomuniversity.ac.id

https://doi.org/10.18280/isi.260511

Received: 23 September 2021

Accepted: 28 October 2021

\author{
Keywords: \\ information system, design thinking, trash \\ bank, requirements analysis, qualitative \\ method
}

\begin{abstract}
The development of system model using the traditional System Development Life Cycle often faces big problems. One of the biggest problems is determining the process model. The existing requirements analysis method is not good enough in producing process model. There are many invalid process models, although they have gone through a series of observations on users. To deal with this, a 'soft' or human-centered method is therefore required. Problems are seen and determined from the point of view of the people involved in the problems. One method that can be used to solve problems is the Design Thinking approach. Design Thinking is the process of creating new ideas and innovative approaches that can solve user problems. This paper proposes the use of an alternative Design Thinking approach in conducting a requirements analysis on the development of Trash Bank system with an interactive qualitative approach. The approach taken is to integrate the concept of Design Thinking in the requirements analysis stage. Through collaboration model the Design Thinking to Requirements analysis, the resulting process model is more valid because the process of exploring the requirements becomes deeper, which is based on user experience. The exploration of user experience from Collaboration model will become the basis for process modeling. According to the approach taken, a more humane and more explored prototype of the system flow is obtained from the human attitude that is involved in the process.
\end{abstract}

\section{INTRODUCTION}

Today the system developers are encouraged to provide low-cost solutions as part of business problems. Management information systems in the process of designing, developing, and managing technological solutions is expected to identify the problems that occur [1]. However, it is often the case that the information systems are pursued in a technical context. When the design and development of information systems are traditionally dominated by technical factors, the problemsolving approaches have caused confusion once the system will be developed in the realm of implementation by the user. In principle, the developers have conducted the user requirements analysis in implementing information systems. This approach, which is inherited from the development of computer systems, relies on the system development life cycle (SDLC) as the primary method [2].

In almost all cases, the systems development life cycle as the main control element, implicitly or explicitly, results in a methodology that adheres to a functional engineering model, takes a structured analysis, a problem-solving approach in which the human complexity in a system is seen as something that can be analyzed and the direction in which the specification can be written [3]. The limitations of technological approach until the late 1970s gave birth to the so-called 'soft' or human-centered method. It is said that the 'hard' or technology-based 'engineering' approach is a traditional approach, which is based on a worldview that sees it as something that is structured, determined, and based on applicable system. The 'soft' method, on the other hand, takes a human-centered attitude, in which the problem is only seen and determined from the point of view of the people involved in the problem [4]. One method that is currently developing is the Design Thinking approach [5]. Design Thinking is the process of creating new ideas and innovative approaches to solve the problems by users [6].

In the last decade, there have been many publications related to the use of Design Thinking. However, not many people associate Design Thinking in the software development process, especially at the requirements analysis stage. Several publications have stated that Design Thinking is indispensable in the requirements analysis. Like study [6] which states that Design Thinking is used as a method to improve User Experience (UX) when interacting with computer software. However, this publication only conveys the benefits of Design Thinking in supporting agile processes at several points. Another study [7] states that Design Thinking introduces new structures and methods to enhance elicitation efforts and inspires a change of mind towards a more human-centered way. The study identified 7 main lessons from using Design Thinking for requirements elicitation, in which each learning is associated with one of the challenge dimensions of the guidance process (process), stakeholder communication (cognition), and quality requirements. Another study related to the use of Design Thinking in requirements engineering is [8] which describes the use of Design Thinking in designing game software. However, in this study, only the stages of integration of the agonist method with Design Thinking are described.

There is quite an interesting study on the use of Design Thinking in software development using tools, namely 
DTA4RE [9]. The results of the study indicate that the use of DTA4RE has helped in the selection and learning of Design Thinking techniques when considering real problems that occur in the field. However, this study only focuses on surveying the efficiency and effectiveness of using the DTA4RE tool among software engineering students, graduate students, and industry professionals. Another study combines The Agile Design Data Modeling (ADDAM) with Design Thinking [10]. The results of the study indicate the fact that in the development of information systems, the non-technical factors around people and organizational culture are much more significant than technological and data-related factors. Then there is a study that maps the Design Thinking process in the software development process and the steps related to the efficient use of Design Thinking in the software development stages [11]. The measurements made show the importance of the designer's role in each stage of software development. From all existing study, it shows that Design Thinking is an important concept in software development. However, no one clearly explains how to integrate Design Thinking in requirements analysis. This paper shows proportionally how the role of Design Thinking in requirements analysis. Step by step is explained through the case study used in the research. The case study used is the development of a Trash Bank model. Trash Bank is a concept of collecting and sorting waste and having proper banking management. However, what is saved is not money but garbage. People who save are also called customers and can borrow money that will be returned with waste for the money borrowed [12]. The waste is stored and then weighed and rewarded with a sum of money which will be sold at the factories that have cooperated. Meanwhile, plastic packaging can be used by the local community to be recycled into handicrafts. The real purpose of Trash Bank is not the bank itself. Trash Bank is a strategy to increase public awareness to be 'friends' with waste to get direct economic benefits from it. The technology era is an excellent medium for developing the Trash Bank system and providing education to the community because of the massive and mass nature of technology.

The waste problem is currently the biggest problem for Indonesian [13]. It has long been a habit for most Indonesians not to care about waste. It can be seen how the habit of littering in the end has an impact on the environment. One of the efforts is to provide various counseling to the community regarding the waste problems [14]. However, this does not seem to have much effect on people's habits of disposing the waste. One of the ideas is to introduce the concept of a Trash Bank to the community. How to develop a Trash Bank in this context will use a Design Thinking approach, so that the system built is more responsive and able to answer human needs related to Trash Bank.

The next section of this paper is organized into the following sections: Section 2 describes the literature, methods, and research pathways used in this research, Section 3 provides an explanation of the research proposal including the position and contribution of the research, Section 4 contains the results of research related to the use of the concept of Design Thinking in requirements analysis, Section 5 contains a discussion related to the results obtained in the research, and Section 6 contains conclusions and future research opportunities of this research.

\section{METHOD}

The method used in this model is requirements analysis with an interactive qualitative approach with case study. Interactive qualitative research with case study is a "one system" research. This unit can be a program, activity, event, or group of individuals bound by a certain place, time, or bond. A case study is a study that aims to collect data, extract meaning, and gain an understanding of the case [15]. Cases are not representatives of the population and are not intended for population conclusions. This approach is very good to use because it puts forward stories and arguments about a phenomenon.

The advantage of an interactive qualitative approach in case study is that it allows researchers to test theories into situations that are often not as easy or simple as theoretical assumptions [16]. By testing the theory into real conditions, researchers can see how the theory can explain or even fail to explain complex phenomena. The drawback of this approach is that the case study conclusions only apply to cases. Each case is unique or has its own characteristics that are different from other cases. Therefore, the results will be different when researching the same thing with the same approach in different places. A case can consist of one unit or more than one unit, but it is a unit [17]. The steps carried out in the research are as shown in Figure 1.

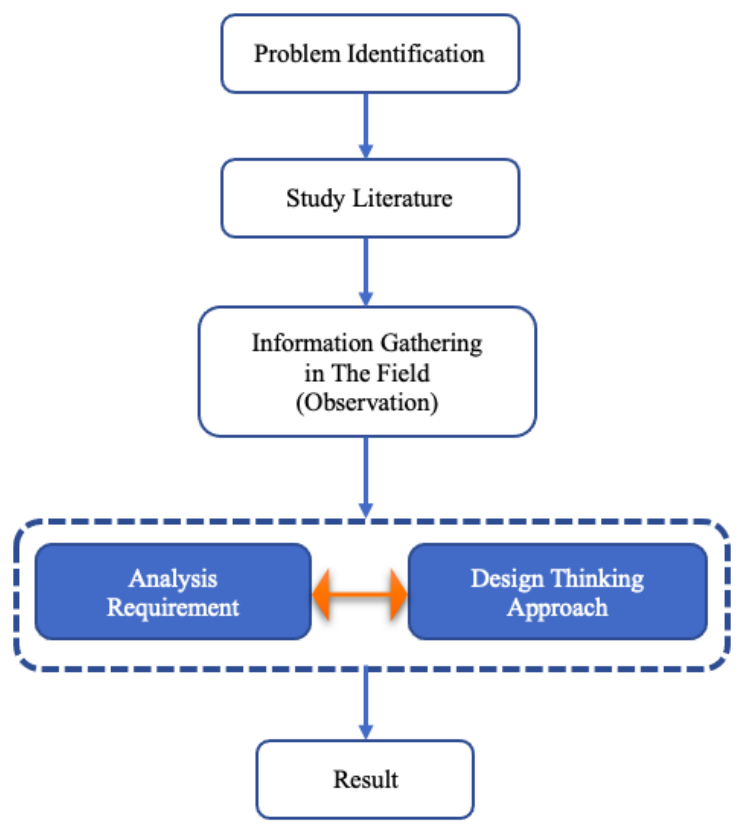

Figure 1. Research flow

Figure 1 shows the research flow with the following explanation:

(1) Problems Identification

In this step, identify the problem in the case study that is the focus of attention.

(2) literature Study

Literature study was conducted to enrich information related to the problems that occurred in the case study.

(3) Gathering Information in the Field (Observation)

This stage is carried out after understanding the problems that occur, then conducting observations in the field by determining the observation domain, the roles involved, and the processes that occur. 
(4) Requirements Analysis Model with Design Thinking Approach

This section is principally the final part of the observation. Requirements analysis is done by using Design Thinking approach. All aspects of human behavior are explored with a Design Thinking model approach to get a prototype picture that will be developed into a system.

(5) Results

In this section, the final results are obtained regarding the implementation of the use of Design Thinking in requirements analysis.

\section{PROPOSED WORK}

The system development life cycle (SDLC) generally uses the waterfall method, in which each step is carried out in a linear sequence and generally requiring the completion of one stage before the next stage begins. Therefore, for example, working on a system design will not be allowed until the system specifications are written and approved. User specification requirements are sometimes incorrect in this process, as these requirements are rarely defined but vary during the project. Developers are showing varying degrees of success at tackling this, and many have become very adept at accommodating changes when requested. This reflects the position reached in the early 1990s, in which the Waterfall model can be identified as the basis for most information systems development $[18,19]$. The alternative argument for a technology-based approach is supported by the findings of several studies on system failure. A study by the OASIG group in 1996 concluded that up to 90 percent of investments in information technology do not meet the performance goals set for them. Lack of attention to human and organizational factors is a major problem in the failure of applied information technology [20].

Software Requirements Analysis is part of the early activities of the software development life cycle. For large software projects, requirements analysis is carried out after the systems/information engineering and software project planning stages [19]. By adopting the notion of requirements in the previous explanation, the requirements analysis can be interpreted as follows:

(1) The process of studying user needs to obtain a system definition or software requirements [21].

(2) The process for determining the functionality and performance of the software, including the interface of the software with other system elements, and determining the obstacles that the software must face [19].

The purposes of conducting a requirements analysis are [22]:

(1) Understanding the problems thoroughly (comprehensive) that exist in the software that will be developed as the scope of the software product (product space) and the users who will use it.

(2) Defines what the software must do to meet customer needs.

An overview of the requirements analysis can be seen in Figure 2.

Figure 2 shows in general the steps taken in conducting a requirements analysis. The first stage is to draw a context diagram related to the focus of requirements. The second stage is to develop a prototype. In some literature this stage can be ignored or included in the next stage, namely the model requirements stage. Requirements modeling is the stage used to bridge between the general system description and the design model. The final stage is the requirements finalization stage [23]. In principle, as explained at each stage, requirements analysis is to answer the question 'what do the users need and want from a new system?'.

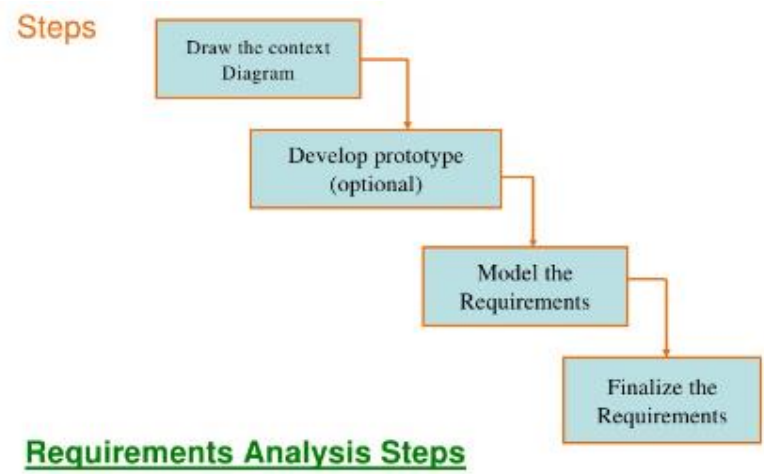

Figure 2. Requirements analysis diagram [23]

\subsection{Human-centered method}

Many examples are available for a human-centered information systems, including soft systems methodologies and interactive planning, which rely on a more holistic perspective. To understand information systems, technology, organizations, and human activities need to be handled interdependently and not separately. Many interactive planning has been done for the development of information systems, providing a good example of a human-centered approach.

The goal of interactive planning in general is to establish a system view as a concern through the eyes of those involved and to use these resources to manage the systems development process. In principle, interactive planning works backwards through the steps of setting goals and identifying goals. Once this is done, it means that this can be selected to fulfill the purpose. So, the core of the planning process is the ideal design, namely the design of the desired system now, not for the future [24]. One method for determining solutions based on human is Design Thinking. In its simplest sense, Design Thinking is the process of creating new and innovative ideas to solve problems. It is not limited to any particular industry or area of expertise. Design Thinking is very useful in terms of technology, as well as services and products [25]. Its presence can create new products and services for customers, in order to increase productivity in its operational processes. The five stages of Design Thinking are as follows: Empathy, Define, Ideate, Prototype, and Test [10]. In this context, there is an opportunity to improve the method which is usually done by applying Design Thinking in perfecting the requirements analysis stage.

\subsection{Combining requirements analysis methodology and design thinking}

The approach taken is shown in Figure 3.

Figure 3 shows a model for determining the context of problems in system development. Then the exploration is focused on the user aspect with empathize, define, and ideate 
approaches. The development of prototypes and models is based on the requirements of the prototype that received input from the previous stage and to complete the requirements analysis based on testing as feedback to strengthen the results of the requirements analysis obtained. The details can be seen in Table 1.

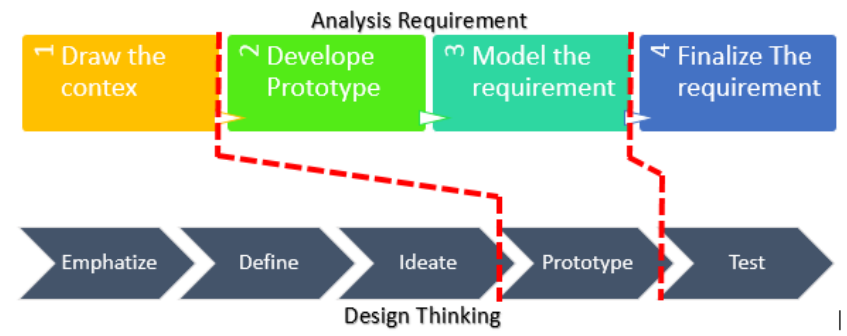

Figure 3. Requirements analysis and design thinking collaborative model

Table 1. Requirements analysis and design thinking collaboration

\begin{tabular}{|c|c|c|c|}
\hline No & $\begin{array}{c}\text { Requirements } \\
\text { Analysis }\end{array}$ & $\begin{array}{c}\text { Design } \\
\text { Thinking }\end{array}$ & Model \\
\hline 1 & $\begin{array}{l}\text { Draw The } \\
\text { Context }\end{array}$ & $\begin{array}{c}\text { Emphatize, } \\
\text { define, dan } \\
\text { ideate }\end{array}$ & $\begin{array}{c}\text { Create Vision Board } \\
\text { Collect Data \& } \\
\text { Define Persona with } \\
\text { Design Thinking } \\
\text { map }\end{array}$ \\
\hline 3 & $\begin{array}{l}\text { Develope } \\
\text { Prototype } \\
\text { Model The } \\
\text { Requirements }\end{array}$ & Prototype & Prototype Model \\
\hline 4 & $\begin{array}{l}\text { Finalize The } \\
\text { Requirements }\end{array}$ & Test & Build and Test \\
\hline
\end{tabular}

\section{RESULT}

In building a system, of course, we can refer to the system development life cycle. The crucial stage is the communication stage between developers and users or stakeholders or commonly called the requirements analysis stage. Requirements analysis is done to gain a clear understanding of the needs and objectives of stakeholders and end users. To explore the wishes of stakeholders and end users will require a methodology that can accurately provide answers. Design Thinking can provide significant results for this because it involves empathy from the end user as a basis in determining solutions.

\subsection{Mapping stage of design thinking on requirements analysis}

The design thinking collaboration stage in requirements analysis is as follows:

(1) Create Vision Board;

(2) Mapping of Design Thinking;

(3) Drawing the Prototype;

(4) Finalization of the Requirements analysis.

The details of the implementation of the stages are as shown in the following explanation.

\subsubsection{Create vision board}

To determine the overall vision of the system to be built, it can be started from questions such as:

(1) What is the vision of the system to be built?

(2) Who is the target of the system to be built?

(3) What are the requirements in building the system?

(4) What are the main functions of the system to be built?

(5) How to determine the business value of the system to be built?

(6) How to measure the success of the system to be built?

With these questions, we can determine the overall Vision Board as shown in Table 2.

\subsubsection{Mapping of design thinking}

To conduct Design Thinking mapping, you can use Think \& Feel, Hear, See, Say and Do by collecting data through questions to obtain system user personas. Figure 4 will show the mapping process.

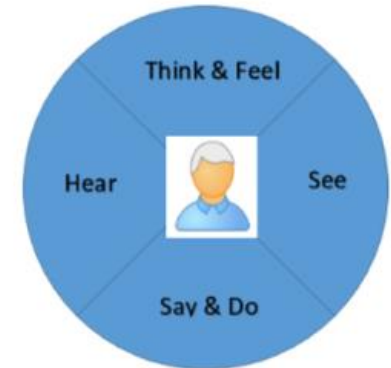

Figure 4. Design thinking map [26]

Table 2. Vision board

\begin{tabular}{|c|c|c|c|}
\hline \multicolumn{4}{|c|}{$\begin{array}{l}\text { Vision is building a Trash Bank system capable of supporting the process of waste management as well as providing education to the } \\
\text { community }\end{array}$} \\
\hline System Target & Needs & Key Features of System & Business value \\
\hline $\begin{array}{l}\text { Secondary } \\
\text { Trash Bank, } \\
\text { Waste Collectors }\end{array}$ & $\begin{array}{l}\text { Web Portal for the management of Trash } \\
\text { Bank mechanism that can be accessed by } \\
\text { Trash Bank and the community } \\
\text { Ease of Use of mobile applications to support } \\
\text { the interaction between the community and } \\
\text { Trash Bank managers }\end{array}$ & $\begin{array}{l}\text { Management and Calculation } \\
\text { banking mechanism in the Trash Bank } \\
\text { customer's account } \\
\text { Registration for Trash Bank like } \\
\text { waste collectors } \\
\text { Mobile-based Registration for people } \\
\text { who need Trash Bank } \\
\text { Detect the Presence of a nearby Trash } \\
\text { Bank }\end{array}$ & $\begin{array}{l}\text { The System Can Give Money } \\
\text { value for people who collect } \\
\text { waste } \\
\text { The system is able to provide } \\
\text { education on Trash Bank } \\
\text { Integrated Management of } \\
\text { national and international } \\
\text { Can be Accessed by the } \\
\text { community wherever the user } \\
\text { is located }\end{array}$ \\
\hline \multicolumn{4}{|c|}{$\begin{array}{l}\text { The size of the success of the system to be built are: } \\
\text { 1. The number of customers continues to grow } \\
\text { 2. The amount of Trash Bank available to national scale }\end{array}$} \\
\hline
\end{tabular}


Here is a list of questions to explore empathy, determination and ideas.

Think and Feel (Now and Dreams)

(1) What is the most important thing in waste management?

(2) What do you want from the environment? Especially about garbage?

(3) In your opinion, what does make you reluctant to throw garbage in its place?

(4) Do you think sorting waste is a hassle? Why?

(5) What do you think if you see piles of garbage around your neighborhood?

(6) What can you do with the waste in your home?

Hear (Influence)

(1) What do you hear from other people about waste?

(2) Who does keep your environment clean?

(3) In your opinion, is there anything that could influence you so that you can participate in waste management?

(4) What does make you realize the importance of disposing the waste properly?

(5) Have you heard of the Waste Bank? From where? Is it from other people, magazines, or electronic media? Is it from the internet or social media?

See (Environtment)

(1) Do you see the impact of waste on your environment? What impact?

(2) Do you know how to manage waste?

(3) Is there a lot of garbage in your home, office, car, and around you?

(4) Are there still many people around you who don't care about cleanliness?

(5) When asked to rate from 1-10, in which 1 is the dirtiest and 10 is the cleanest, for the environment around you, how would you rate its cleanliness?
Say and Do (Behaviour, Attitude, and Habit)

(1) What do you do or say when you see people throwing garbage in its proper place, such as in rivers, roadsides and so on?

(2) What would you do if you saw garbage in front of you?

(3) If there are conditions due to the impact of waste, what will you do?

(4) How do you familiarize your family with environmental awareness?

(5) What do you do if you want to take out the garbage, but cannot find a landfill?

\subsubsection{Drawing the prototype}

This step will be done after getting the results of the Design Thinking mapping. Some thing you can do is Brainstorm related to the results of the Design Thinking mapping:

(1) Create user (end users) pathway;

(2) Encourage innovative ideas;

(3) Make a prototype from the results of Design Thinking.

Figure 5 shows the prototype of user pathway generated by the Design Thinking approach in the general flow of modeling a Trash Bank system. The process shows that each activity produced is obtained based on the Design Thinking approach carried out in the previous stages. Activities are made based on user needs, which are explored through the Design Thinking approach.

\subsubsection{Finalization of requirements analysis}

This step is carried out as a step to complete the requirements analysis, in which there are two important things that must be done, namely:

(1) Collecting feedback from end users in prototype;

(2) Complete the prototype.

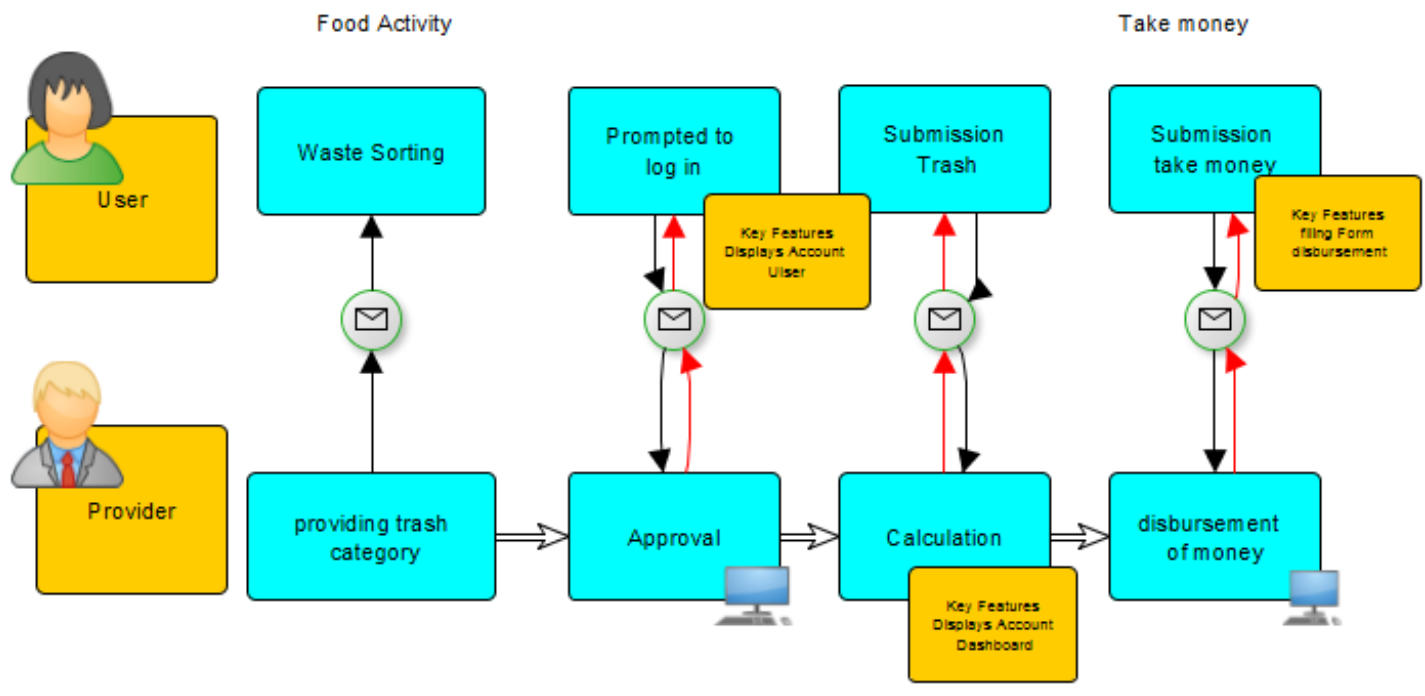

Figure 5. User pathway

\section{DISCUSSION}

The collaboration between requirements analysis and design thinking provides very powerful results in process modeling. Requirements analysis with the traditional approach is usually dominated by the idea of a system developer, even if there is user exploration by the developer, it is carried out in a random, un patterned form. Meanwhile, by integrating the design thinking mechanism in the requirements analysis, the modeling results will be much better. Design thinking patterns are based on user experience. By applying the exploration step of design thinking, the exploration of user experience will become the basis for process modeling. When the user has an extraordinary experience in some of the actual context of the case study, in this case, the trash bank model will be an important developer note. This research in detail describes the Collaboration contribution of Design Thinking and Requirements analysis as shown in Figure 6. 


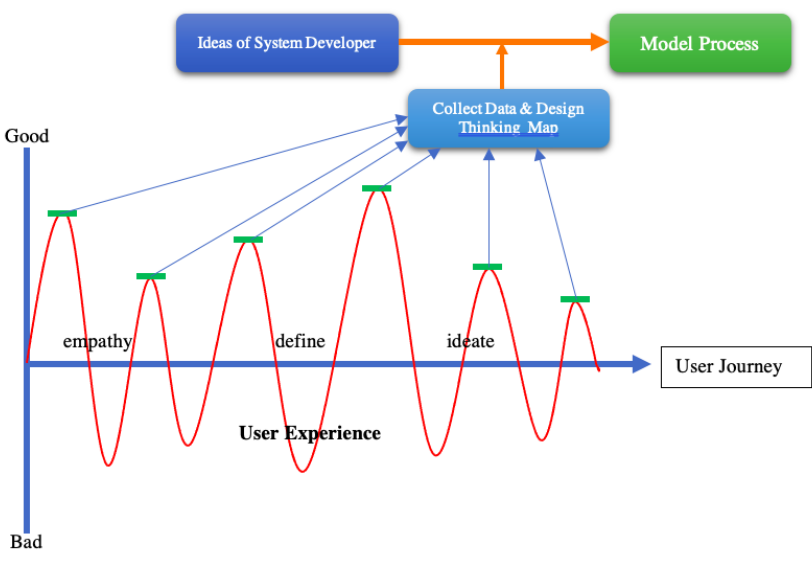

Figure 6. Schematic of collaboration of requirements analysis and design thinking in process modeling

Figure 6 shows that the collaboration scheme has far advantages over the traditional exploration concept. The ideas owned by the system model developer will be validated by the Design Thinking mechanism through user experience exploration. With stages like this, the Trash bank process model will become more humane and on target according to user needs.

The collaboration of requirement analysis and design thinking has important and advantage points that are of concern in this study, namely:

(1) This collaboration can determine the user experience and analyze more deeply the user's needs.

(2) This collaboration can increase the point of service satisfaction by optimizing the trash bank process model.

(3) The results of the collaboration can be made for development planning (roadmap for developing the trash bank system model).

(4) The results of the collaboration can directly answer the problems in the community.

(5) This collaboration is a scheme so that the developer's ideas are valid and can be felt by users.

(6) This collaboration can synthesize the developer's findings in order to find out the problems that are felt directly by trash bank users.

The research process was carried out using a case studybased Qualitative Interactive Method approach, and during the process produced many analytical documents. So, the drawback of this paper is that not all analytical documents are submitted. This paper only conveys important points that contribute to the research. However, with the presentation presented, other researchers who are interested in process modeling research, especially with a qualitative approach, can take advantage and develop other better alternative methods.

\section{CONCLUSION \& FUTURE WORKS}

In building a system requirements analysis, design thinking has a clear approach in exploring the needs of system users. This is because the focus of design thinking is to explore user empathy, especially end users, in order to obtain clarity regarding the results of the analysis of the system that needs to be built. This research succeeded in collaborating the concept of traditional needs analysis with the concept of design thinking so as to produce a new scheme that is better in producing process modeling. With collaboration schemes, user experience becomes the main reference. With a collaborative approach between needs analysis and design thinking, the resulting prototype becomes clearer. The flow of the process model becomes more humanism and rich with information from the behavior of humans involved in the process of the Trash bank system.

The collaborative approach used in this research will be an opening in the future in process modeling research. Several related matters that can be developed are related to the model development plan, process model improvement, and problem synthesis in process modeling. with the entry of the industrial revolution 4.0 through the phenomenon of collaborating cyber technology and automation technology will make the processes running in the community more complex and become a challenge in itself in implementing the collaborative methods produced in this paper in the future.

\section{ACKNOWLEDGMENT}

This work was supported by LPPM PGRI Yogyakarta University and PPM Telkom University in the completion of this research and in particular, we thank to Aris Hermansyah, Lecturer in Department of Management STEMBI Bandung for his input related to the language structure presented in this paper.

\section{REFERENCES}

[1] Laudon, K.C., Laudon, J.P. (2015). Management Information Systems. Upper Saddle River: Pearson., 2015.

[2] Hirschheim, R., Klein, H.K., Lyytinen, K. (1995). Information Systems Development and Data Modeling: Conceptual and Philosophical Foundations. Cambridge University Press.

[3] Ludewig, J. (2004). Models in software engineering - An introduction. Inform. - Forsch. und Entwicklung, 18(3-4) 105-112. https://doi.org/10.1007/s00450-004-0155-7

[4] Clarke, S. (2010). Information Systems Strategic Management; A Integrated Approach. London \& New York: Routledge, Taylor \& Francis Group., 2010.

[5] Vetterli, C., Brenner, W., Uebernickel, F., Petrie, C. (2013). From palaces to yurts. IEEE Computer Society, 13: 91-94. https://doi.org/10.1109/MIC.2013.32

[6] Husaria, A., Guerreiro, S. (2020). Requirement engineering and the role of design thinking. in ICEIS 2020 - Proceedings of the 22nd International Conference on Enterprise Information Systems, 2: 353-359. https://doi.org/10.5220/0009489303530359

[7] Hehn, J., Uebernickel, F. (2018). Towards an understanding of the role of design thinking for requirements elicitation - findings from a multiple-case study. in Americas Conference on Information Systems 2018: Digital Disruption, AMCIS 2018, 2018, pp. 1-10.

[8] Piras, L., Dellagiacoma, D., Perini, A., Susi, A., Giorgini, P., Mylopoulos, J. (2019). Design thinking and acceptance requirements for designing gamified software. Proc. - Int. Conf. Res. Challenges Inf. Sci., 2019: 81-92. https://doi.org/10.1109/RCIS.2019.8876973

[9] Souza, A., Ferreira, B., Valentim, N., Correa, L., Marczak, S., Conte, T. (2020). Supporting the teaching 
of design thinking techniques for requirements elicitation through a recommendation tool. IET Softw., 14(6): 693701. https://doi.org/10.1049/iet-sen.2019.0300

[10] O'Driscoll, K. (2016). The agile data modelling \& design thinking approach to information system requirements analysis. J. Decis. Syst., 25: 632-638. https://doi.org/10.1080/12460125.2016.1189643

[11] Canedo, E.D., da Costa, R.P. (2018). The use of design thinking in agile software requirements survey: A case study. In book: Design, User Experience, and Usability: Theory and Practice, 642-657. http://dx.doi.org/10.1007/978-3-319-91797-9_45

[12] Salim, R. (2016). Bank Sampah di Indonesia: Menabung Mengubah http://blogs.worldbank.org/eastasiapacific/id/banksampah-di-indonesia-menabung-mengubah-perilaku, accessed on Sep. 03, 2016.

[13] Solihin, M.M. (2018). Sustainable waste management through trash bank in Ragajaya Village, Bogor Regency, West Java Province, Indonesia. Int. J. Progress. Sci. Technol., $9(2)$ :

190-198. http://dx.doi.org/10.52155/ijpsat.v9.2.506

[14] Sabarinah, Z. (2017). The importance of waste management knowledge to encourage household wastesorting behaviour in Indonesia. Int. J. Waste Resour., 7(4). https://doi.org/10.4172/2252-5211.1000309

[15] Yin, R.K. (2009). Case Study Research, Design and Methods. London \& New York: Sage, 2009. https://doi.org/10.33524/cjar.v14i1.73

[16] Myers, M.D. (2019). Qualitative Research in Business \& Management. London \& New York: Sage, 2019.
[17] Maxwell, J.A. (2012). Qualitative Research Design: An Interactive Approach: An Interactive Approach. Sage, 2012.

[18] Adnan, N.H., Ritzhaupt, A.D. (2018). Software engineering design principles applied to instructional design: What can we learn from our sister discipline? TechTrends, 62(1): 77-94. https://doi.org/10.1007/s11528-017-0238-5

[19] Pressman, R.S., Maxim, B.R. (2010). Software Engineering: A Practitioners Approach. New York: McGraw-Hill.

[20] Anandarajan, M., Simmers, C.A. (2003). Managing web usage in the workplace: A social, ethical and legal perspective. IGI Global. https://doi.org/10.4018/978-1930708-18-1

[21] Escalona, M.J., Koch, N. (2003). Requirements engineering for web applications-a comparative study. Journal of web Engineering, 2(3): 193-212.

[22] Sommerville, I. (2011). Software Engineering. 9th Edition. Addison Wesley Publishing Company, 2011.

[23] Pfleeger, J.M., Atlee, S.L. (1998). Software Engineering: Theory and Practice. Pearson Education India.

[24] Ackoff, R.L. (2001). A Brief Guide to Interactive Planning and Idealized Design. Lancaster, 2001.

[25] Meinel, C., Leifer, L., Plattner, H. (2011). Design Thinking. Springer-Verlag Berlin Heidelberg.

[26] Lewrick, L., Link, P., Leifer, L. (2018). The Design Thinking Playbook: Mindful Digital Transformation of Teams, Products, Services, Businesses and Ecosystems. Chicago: John Wiley \& Sons. 